\title{
Uncovering the Barriers to Exclusive Breast Feeding for Mothers in a Rural Setting in Southern India
}

\author{
(1) Supriya Venkatachalapathi1, (1) Alexander Mannu¹, (1) Kathir Subramaniyam¹, () Jaishree Vasudevan², \\ (1) Umadevi Lala1
}

${ }^{1}$ Chettinad Hospital and Research Institute, Department of Pediatrics, TamilNadu, India

${ }_{2}^{2}$ Tagore Medical College and Hospital, Department of Pediatrics, Chennai, India

\begin{abstract}
Aim: Exclusive breastfeeding (EBF) is very important for the growth and development of the baby. The purpose of this study was to identify the prevalence of EBF practices, to assess the factors associated with those practices, and to find the barriers to EBF practices in the rural community.

Materials and Methods: A cross-sectional study based on systematic questioning was carried out involving 252 mothers with children between the ages of 6 and 9 months in the southern Chennai community and the nearby districts of Chengalpattu and Kanchipuram from October 2018 to October 2019. Multiple logistic regression was used to determine factors associated with EBF.

Results: Seventy percent (184/252) of mothers following EBF habits had a child older than six months. About $58 \%$ of mothers started breastfeeding within one hour of birth, and $32.53 \%$ reported colostrum feeding. An apparent shortage of milk (58.82\%) was a common problem reported by the mothers leading to EBF discontinuation. Children of working mothers [Odds ratio (OR) 3.32; $95 \%$ confidence interval (CI) 1.13 , 9.70], urban dwellers (OR 6.67; 95\% Cl 1.12, 39.66) and children in urban areas (OR 12.47; 95\% Cl 2.05, 75.90) were less likely to be breastfed exclusively as indicated in the multivariate regression analysis. No relationships were found between the child's gender, method of childbirth, medical advice, or nutritional management before meals and EBF.
\end{abstract}

Conclusion: Working mothers and those living in urban areas were at greater risk of non-compliance with EBF. The national impact of urban sprawl and the impact on EBF activities should be studied in depth.

Keywords: Breastfeeding, exclusive, habits, community

\section{Introduction}

Exclusive breastfeeding (EBF) is defined as exclusively breastfeeding for the initial six months of life excluding oral rehydration solution (ORS), drops of medicine, or syrups (vitamins, minerals) (1). EBF promotes physical and mental health during childhood and beyond (2-6). In addition to EBF for 6 months as a universal recommendation, with its proven links in improving child survival and reducing illnesses (7-9); only 37-39\% of babies in low- and middleincome countries have breastfeeding money $(10,11)$. 
In India, breastfeeding is the norm and meets EBF's global targets (12). A recent national study estimated that the country's EBF levels are about 55\% (13). However, a survey from various urban slums of India found very low estimated rates of $8 \%$ to $37 \%$ (14-19).

Various publications are available regarding EBF practices from a variety of contexts. The mother's experience of childbearing and rearing is strongly influenced by social norms and ideas, cultures, and personal thoughts. Therefore, it is difficult to integrate EBF practice decisions, but research has shown that EBF levels are linked to maternal age, education, employment; infant sex, age, access to health care, accommodation and multi media exposure or counselling (20-24). Other factors contributing to EBF are the history of maternity visits, prenatal counselling, influence from health care providers, early nutrition, early onset, and type of delivery (25-27). The direction and magnitude of these organizations, however, were not universal, and this points to the strong influence of contextual approaches to EBF actions. One of the most frequently identified barriers to EBF in various studies and cases is inadequate breast milk $(17,28)$.

However, evidence surrounding feeding practices is limited to the Tamil Nadu region, which is why this study investigated the status of EBF practices, examined the factors associated with these practices, and identified barriers to EBF practices in the community.

\section{Materials and Methods}

\section{Study Design and Sample Selection}

A community-based study was conducted in the southern state of Chennai and in the combined districts of Chengalpattu and Kanchipuram from October 2018 to October 2019. All 6-to 9-month-old infants were enrolled and a simple evaluation application was made to recruit study participants. The study approval was obtained from the Ethics Committee, Chettinad Hospital and Research Institute (No. 92/IHEC/12-16) and written approval was obtained from all participants.

\section{Variable Options}

Independent variables were selected based on extensive literature reviews. The maternal characteristics recorded were age, education, occupation, type of family, place of residence, number of maternity visits, delivery method, lactation counselling, breastfeeding initiation, frequency of feeding, feeding habits before childbirth, gender, use of a neonatal intensive care unit and birth order. In the case of working mothers, years of current work, working hours, type of leave available, kindergarten availability, whether the child is allowed at the work place, nursing leave, night shifts, and the presence of a non-mother caregiver were also assessed.

\section{Data Collection}

Face-to-face questions were asked to the mothers about their breastfeeding habits. They are abbreviated as EBF (breast milk excluding ORS, drops of medicine, syrups up to six months in total) and non-breastfeeding (1). Some of the information collected includes the variables as described above.

\section{Statistical Analysis}

Data were analyzed with SPSS Version 20.0 software. Descriptive analysis was performed to reveal the required number of people to research the characteristics of the infants and mothers. A simple adjustment of the settings was used to determine the relationship between each variable and the state of the different effects -EBF- and l. Results are shown as inconsistencies in p-values. The variables considered to be included in most analyses were selected with respect to the previous literature $(3,15,23,27)$. All variables with a $p$-value of less than 0.20 in bivariate analysis were taken, after adjusting for other variables. Age and gender were considered static and adjusted to the final model. Corresponding factors of $p<0.05$ were considered statistically significant.

\section{Results}

A total of 252 mothers with infants under 9 months of age were interviewed in this study. Descriptive sample analysis, divided into feeding performed only for six months, is presented in Table I. The prevalence of EBF was found to be $73.01 \%$. More than half of the mothers (51.58\%) reported being working mothers, and $42.9 \%$ had received basic education. Before giving birth, $89.68 \%$ of mothers had received medical advice and planned to breastfeed their babies for at least six months. About $66 \%$ of mothers received 4 or more check-ups before delivery and 51.5\% received maternity care. They were all brought to the clinic. About half $(52.38 \%)$ of the mothers underwent surgical resection.

This study found that $58.72 \%$ of mothers started breastfeeding within one hour of birth, but only $32.53 \%$ reported colostrum. In addition, $19.80 \%$ of mothers reported pre-lacteal treatment, providing anything other than breast milk for babies in the first three days of life. 
Honey $(33.42 \%)$, sugar water $(19.73 \%)$, plain water $(15.81 \%)$, and infant formula (8.92\%) were infant formula-fed. Of the participants, $26.98 \%$ reported stopping breastfeeding before the age of six months. Of them, 8.82\% stopped EBF at 1 month, $11.76 \%$ at both 2 and 3 months, 29.41\% at four months and $38.23 \%$ at five months. The mother's response to questions about the problems that led to breastfeeding discontinuation was not revealed (23.52\%), due to sore nipples $(14.70 \%)$, due to breast implants $(2.94 \%)$ or due to poor milk supply (58.82\%).
In the final model of relapse after rehabilitation $(p<0.2)$ we found that children of working mothers [Odds ratio (OR) 3.32; 95\% confidence interval (CI) 1.13, 9.70], urban dwellers (OR 6.67; 95\% Cl 1.12, 39.66) and those in urban areas (OR $12.47 ; 95 \% \mathrm{Cl} 2.05,75.90)$, and those brought to a public hospital (OR 5.45; 95\% Cl 1.44, 20.60) had little chance of EBF. There were absolutely no relationships found between the child's sex, type of delivery, breastfeeding counselling, or first feeding and EBF (Table II).

Table I. Descriptive statistics of the sample stratified by exclusively breastfed for 6 months

\begin{tabular}{|c|c|c|c|c|c|}
\hline \multicolumn{2}{|l|}{ Parameters } & Total $(n=252)$ & No EBF $(n=68)$ & $\operatorname{EBF}(n=184)$ & p-value \\
\hline \multirow{3}{*}{ Mother's Age } & $<20$ & 5.55 & 5.88 & 5.43 & 0.54 \\
\hline & $20-30$ & 69.84 & 76.47 & 67.39 & \\
\hline & $>30$ & 24.60 & 17.64 & 27.17 & \\
\hline \multirow{2}{*}{ Family type } & Nuclear & 52.38 & 47.05 & 54.34 & 0.29 \\
\hline & Joint & 47.61 & 52.94 & 45.65 & \\
\hline \multicolumn{2}{|l|}{ Working mother } & 48.41 & 67.64 & 41.30 & $0.01^{*}$ \\
\hline \multirow{3}{*}{ Employed in } & Urban & 47.61 & 47.05 & 47.82 & $0.02^{*}$ \\
\hline & Semi-Urban & 29.36 & 44.11 & 23.91 & \\
\hline & Rural & 23.01 & 8.82 & 28.26 & \\
\hline \multirow{2}{*}{ Sex of baby } & Female & 51.58 & 47.05 & 53.26 & 0.55 \\
\hline & Male & 48.41 & 52.94 & 46.73 & \\
\hline \multirow{3}{*}{ Birth order } & 1 & 64.28 & 17.46 & 64.13 & 0.74 \\
\hline & 2 & 33.59 & 32.35 & 34.78 & \\
\hline & 3 & 1.58 & 2.94 & 1.08 & \\
\hline \multirow{2}{*}{ Place of delivery } & Govt Hospital & 17.46 & 32.35 & 11.95 & $0.01^{*+}$ \\
\hline & Private Hospital & 82.53 & 67.64 & 88.04 & \\
\hline \multicolumn{2}{|l|}{ NICU admission } & 20.63 & 17.64 & 21.73 & $0.80^{\dagger}$ \\
\hline \multicolumn{2}{|l|}{ Lactation counseling } & 89.68 & 88.23 & 90.21 & 0.74 \\
\hline \multirow[t]{4}{*}{$\begin{array}{l}\text { Initiation of } \\
\text { breastfeeding }\end{array}$} & Immediately & 32.53 & 32.35 & 32.60 & 0.81 \\
\hline & Less than 1 hour & 26.19 & 26.47 & 26.08 & \\
\hline & $1-2$ hours & 22.22 & 17.64 & 23.91 & \\
\hline & $>2$ hours & 19.05 & 23.52 & 17.39 & \\
\hline \multirow[t]{3}{*}{$\begin{array}{l}\text { Frequency of feeds } \\
\text { (times) }\end{array}$} & $<8$ & 14.28 & 32.35 & 7.60 & $0.000^{*}$ \\
\hline & $8-14$ & 84.92 & 64.70 & 92.39 & \\
\hline & $\geq 15$ & 0.79 & 2.94 & 0.00 & \\
\hline \multicolumn{2}{|l|}{ Prelacteal feeds } & 19.80 & 35.29 & 14.13 & $0.01^{* \dagger}$ \\
\hline \multicolumn{2}{|l|}{ Gripe water } & 34.12 & 55.88 & 26.08 & $0.003^{*}$ \\
\hline
\end{tabular}


In further analysis to determine the reasons behind high non-EBF, significant differences were found between both groups in terms of breaks $(p=0.03)$ and night shifts $(p=0.02)$. However, it has also been noted that working years, working hours, or type of leave did not affect the discontinuation of breastfeeding (Table III).

Table II. Multivariate Logistic Regression between maternal parameter sand lack of exclusive breast feeding

\begin{tabular}{|c|c|c|c|c|c|}
\hline \multirow{2}{*}{\multicolumn{2}{|c|}{$\begin{array}{l}\text { Parameters } \\
\text { OR }^{\mathrm{a}}\end{array}$}} & \multicolumn{2}{|c|}{ Univariate Analysis } & \multicolumn{2}{|c|}{ Multivariate Analysis } \\
\hline & & \multirow{2}{*}{$\begin{array}{l}\text { p-value } \\
2.91(1.29-6.81)\end{array}$} & \multirow{2}{*}{$\frac{\mathrm{aOR}^{\mathrm{b}}}{0.01^{*}}$} & \multirow{2}{*}{$\begin{array}{l}\text { p-value }{ }^{\text {b }} \\
3.32(1.13-9.70)\end{array}$} & \multirow[b]{2}{*}{$0.02^{*}$} \\
\hline Working mother & Yes & & & & \\
\hline & No (Ref) & & & & \\
\hline \multirow[t]{3}{*}{ Employed in } & Urban & $3.15(0.83-11.85)$ & 0.09 & $6.67(1.12-39.66)$ & $0.03^{*}$ \\
\hline & Semi-urban & $5.90(1.51-23.10)$ & $0.01^{*}$ & $12.47(2.05-75.90)$ & $0.006^{*}$ \\
\hline & Rural (Ref) & & & & \\
\hline \multirow[t]{2}{*}{ Place of birth (Hospital) } & Govt & $3.52(1.35-9.15)$ & $0.01^{*}$ & $5.45(1.44-20.60)$ & $0.01^{*}$ \\
\hline & Private (Ref) & & & & \\
\hline \multirow[t]{2}{*}{ Prelacteal feed } & Yes & $3.31(1.32-8.28)$ & $0.01^{*}$ & $1.07(0.30-3.82)$ & 0.90 \\
\hline & No (Ref) & & & & \\
\hline
\end{tabular}

Table III. Job statistics of working mothers stratified by exclusively breastfeeding for 6 months

\begin{tabular}{|c|c|c|c|c|c|}
\hline \multicolumn{2}{|l|}{ Parameters } & \multirow{2}{*}{$\begin{array}{l}\text { Total }(n=122) \\
9.83\end{array}$} & \multirow{2}{*}{$\begin{array}{l}\text { Non EBF }(n=46) \\
8.69\end{array}$} & \multirow{2}{*}{$\begin{array}{l}\operatorname{EBF}(\mathbf{n}=\mathbf{7 6}) \\
10.52\end{array}$} & \multirow{2}{*}{$\frac{\text { p-value }}{0.61}$} \\
\hline Present job years & $<1$ & & & & \\
\hline & $1-2$ & 19.67 & 26.08 & 15.78 & \\
\hline & $>2$ & 70.49 & 65.21 & 73.68 & \\
\hline \multirow[t]{3}{*}{ Working hours } & $<5$ & 8.19 & 8.69 & 7.89 & 0.99 \\
\hline & $5-8$ & 60.65 & 60.86 & 60.52 & \\
\hline & $>8$ & 31.14 & 30.43 & 31.57 & \\
\hline \multirow[t]{5}{*}{ Leave } & Maternity & 65.57 & 65.21 & 65.78 & 0.54 \\
\hline & Earned & 4.91 & 0.00 & 7.89 & \\
\hline & Commuted & 1.63 & 0.00 & 2.63 & \\
\hline & Partial pay & 6.55 & 8.69 & 5.26 & \\
\hline & Unpaid leave & 2.13 & 26.08 & 2.63 & \\
\hline \multicolumn{2}{|c|}{ Baby allowed in workplace } & 34.42 & 21.73 & 42.10 & 0.10 \\
\hline \multicolumn{2}{|l|}{ Presence of Creche } & 29.50 & 21.73 & 34.21 & 0.30 \\
\hline \multicolumn{2}{|l|}{ Nursing breaks } & 47.54 & 30.43 & 57.89 & $0.03^{*}$ \\
\hline \multicolumn{2}{|l|}{ Night shifts } & 29.50 & 9.67 & 39.47 & $0.02^{*}$ \\
\hline \multirow[t]{4}{*}{ Baby caretaker } & Spouse & 13.11 & 6.45 & 15.78 & 0.69 \\
\hline & In-Laws & 59.01 & 4.51 & 57.89 & \\
\hline & Appointed nanny & 16.39 & 16.12 & 13.15 & \\
\hline & Play home & 11.47 & 6.45 & 13.15 & \\
\hline
\end{tabular}




\section{Discussion}

This study not only investigated the status of EBF practices and their related factors, but also identified post-traumatic stress disorder among mothers with 6- to 9-month-old infants in the southern Chennai community and the combined districts of Chengalpattu and Kanchipuram. This study found that almost half of mothers were working and this affected EBF three times, which also led to further $(29,30)$. Also, urban and urban workplaces pose a significant risk to breastfeeding by a factor of 6 and 12 times respectively, which may be the result of outpouring, while those in rural areas tend to work at home / stay at home with the child. This was based on the discovery of Chen et al. (30).

The rates EBF was found to be higher in our study (73.01\%) compared to the national average from the National Family and Health Survey-4 (55\%) (13). A survey by the Department of Women and Children Development, Government of India, in 2013-2014 found an EBF rate of $65.1 \%$ in rural areas (31). Interestingly, studies conducted in countries such as Jordan (32), Qatar (33), and Saudi Arabia (34) reported extreme low EBF rates of 2.1\%, 24.3\%, 37\% and a better rate of $50.8 \%$ in Sri Lanka (35).

About $58.72 \%$ started breastfeeding within one hour. Of those who could not, $78.21 \%$ failed to do so due to the surgical phase. These findings show that only $47.7 \%$ of mothers at the health care facility start within 1 hour, which indicates an effect of the type of delivery (36). Implementation of breastfeeding was also affected by the surgical interventions received by women among other subjects (37-39). A mother's inability to breastfeed her baby immediately after surgery delayed early initiation. In addition, the initiation of breastfeeding within 1 hour of delivery has also been found as a prediction of continued breastfeeding $(40,41)$. However, this was not the result of our research findings.

Unlike other studies, $32.53 \%$ of children in this study were fed colostrum. Colostrum nutrition was supported by pre-lacteal habits, as found in previous studies. Honey $(33.42 \%)$ and sugar water (19.73\%) were the first reported feeds given to infants in this study. In India, it is common practice to use this as a precautionary measure $(42,43)$. We found that babies who received early breastfeeding were three times more likely to breastfeed especially in bivariate analysis. Prelacteal administration has also been reported as a risk factor for EBF failure in previous studies (44).

Our study did not find that the mother's age was a predictor of EBF. A review of Emmanuel's books has shown the association of maternal age with higher EBF levels (45). Similar studies in rural Uttar Pradesh (46) and southern India (36) found a strong correlation between EBF and maternal age. However, the combined results of systematic reviews obtained, where 7 out of 12 studies did not reveal any relationship between the mother's age and EBF, while the remaining 5 found significant relationships between the two (47).

EBF counselling for mothers, various breastfeeding educational materials, and breastfeeding support videos have been found to be strongly associated with EBF practices in studies conducted in India by Chudasama et al. (48) and Patil et al. (49). All mothers included had at least one visit before delivery, and were all referred to facilities; about $90 \%$ of them received EBF counselling. However, it was not found to have a positive EBF effect in our study. Those who delivered in public hospitals had a fivefold risk of EBF compared to those mothers who delivered in antenatal hospitals. This can be seen in the absence of appropriate advice and funding from the government, although research on this is limited.

\section{Study Limitations}

A few limitations within this study need to be noted. The definition of EBF used here according to 24 hour - recall period is subjected to bias and misreporting. It was difficult for the women to recall the use of some supplements from memory. A different approach such as long-term follow-up with women to see if they are using EBF can produce better evidence of smaller ingredients. In addition, the mother's perception of milk deficiency was present in $58 \%$ of cases, so water or other water management may have been higher than normal. However, we have tried to reduce inaccuracy by including mothers of infants who are 6 to 9 months old in the study. On the other hand, this study was conducted publicly with the required sample size and full response, so there is a good external performance that allows us to reproduce what we have obtained from other people in the country.

\section{Conclusion}

EBF practices among mothers in the community of southern Chennai and the adjoining districts of Chengalpattu and Kanchipuram was found to be higher than the universal levels recommended by the World Health Organization and also was above the national average. Moreover, this study found that working mothers and those residing in urban areas were at higher risk of not adhering to EBF. These finding should be studied in greater depth to 
understand the national impact of increasing urbanization and the impact on EBF practices as well as maternal and infant immediate and long-term health.

\section{Ethics}

Ethics Committee Approval: The study approval was obtained from the Ethics Committee, Chettinad Hospital and Research Institute (No. 92/IHEC/12-16).

Informed Consent: Written approval was obtained from all participants.

Peer-review: Internally and externally peer-reviewed.

\section{Authorship Contributions}

Concept: S.V., A.M., Design: S.V., A.M., K.S., Data Collection or Processing: S.V., A.M., K.S., Analysis or Interpretation: S.V., A.M., K.S., J.V., U.L., Literature Search: S.V., I.V., U.L., Writing: S.V., A.M., Manuscript Review: K.S., J.V., U.L.

Conflict of Interest: No conflict of interest was declared by the authors.

Financial Disclosure: The authors declared that this study received no financial support.

\section{References}

1. World Health Organization. Global Strategy for Baby and Young Child Feeding. Geneva: World Health Organization; 2003.

2. Sankar M), Sinha B, Chowdhury R, et al. Optimal breastfeeding practices and infant and child mortality: a systematic review and meta-analysis. Acta Paediatr 2015; 104:3-13.

3. Horta BL, Loret de Mola C, Victora CG. Breastfeeding and intelligence: a systematic review and meta-analysis. Acta Paediatr 2015; 104:14-9.

4. Horta BL, Loret de Mola C, Victora CG. Long-term consequences of breastfeeding on cholesterol, obesity, systolic blood pressure and type 2 diabetes: a systematic review and meta-analysis. Acta Paediatr 2015; 104:30-7.

5. Lodge C, Tan D, Lau M, et al. Breastfeeding and asthma and allergies: a systematic review and meta-analysis. Acta Paediatr $2015 ; 104: 38-53$.

6. Peres KG, Cascaes AM, Nascimento GG, Victora CG. Effect of breastfeeding on malocclusions: a systematic review and metaanalysis. Acta Paediatr 2015; 104:54-61

7. Black RE, Allen LH, Bhutta ZA, Caulfield LE, de Onis M, Ezzati $M$, et al. Maternal and child undernutrition: global and regional exposures and health consequences. Lancet Lond Engl 2008; 371:243-60.

8. Jones G, Steketee RW, Black RE, Bhutta ZA, Morris SS. How many child deaths can we prevent this year? Lancet Lond Engl 2003; 362:65-71.

9. Kramer M, Kakuma R. Optimal duration of exclusive breastfeeding. Cochrane Database Syst Rev 2012;8:CD003517. doi: 10.1002/14651858.CD003517.pub2.
10. Victora CG, Bahl R, Barros AJD, et al. Breastfeeding in the 21st century: epidemiology, mechanisms, and lifelong effect. Lancet Lond Engl 2016; 387:475-90.

11. Lauer JA, Betrán AP, Victora CG, de Onís $M$, Barros AJD. Breastfeeding patterns and exposure to suboptimal breastfeeding among children in developing countries: review and analysis of nationally representative surveys. BMC Med $2004 ; 2: 26$.

12. Global Nutrition Targets 2025. WHO and UNICEF; (Breastfeeding Policy Brief 2014). Available from: http://apps.who.int/iris/ bitstream/10665/149022/1/WHO_NMH_NHD_14.7_eng.pdf

13. International Institute for Population Sciences (IIPS) and ICF. 2017. National Family Health Survey-4, 2015-16. Mumbai: IIPS; 2016.

14. Velusamy V, Premkumar PS, Kang G. Exclusive breastfeeding practices among mothers in urban slum settlements: pooled analysis from three prospective birth cohort studies in South India. Int Breastfeed ) 2017; 12:35.

15. Tiwari R, Mahajan PC, Lahariya C. The Determinants of Exclusive Breast Feeding in Urban Slums: A Community Based Study. Trop Pediatr 2009; 55:49-54.

16. Aneja B, Singh P, Tandon M, Pathak P, Singh C, Kapil U. Etiological factors of malnutrition among infants in two urban slums of Delhi. Indian Pediatr 2001; 38:160-5.

17. Roy S, Dasgupta A, Pal B. Feeding practices of children in an urban slum of kolkata. Indian I Community Med Off Publ Indian Assoc Prev Soc Med 2009; 34:362-3.

18. Nimbalkar AS, Shukla VV, Phatak AG, Nimbalkar SM. Newborn care practices and health seeking behavior in urban slums and villages of Anand, Gujarat. Indian Pediatr 2013; 50:408-10.

19. Bagul AS, Supare MS. The infant feeding practices in an urban slum of nagpur, India. J Clin Diagn Res 2012; 6:1525-7.

20. Martines JC, Ashworth A, Kirkwood B. Breast-feeding among the urban poor in southern Brazil: reasons for termination in the first 6 months of life. Bull World Health Organ 1989; 67:151-61.

21. Tamiru D, Aragu D, Belachew T. Survey on the introduction of complementary foods to infants within the first six months and associated factors in rural communities of Jimma Arjo. Int I Food Sci Nutr 2013; 2:77-84.

22. Kimani-Murage EW, Madise NJ, Fotso J-C, et al. Patterns and determinants of breastfeeding and complementary feeding practices in urban informal settlements, Nairobi Kenya. BMC Public Health 2011; 11:396.

23. Mekuria G, Edris M. Exclusive breastfeeding and associated factors among mothers in Debre Markos, Northwest Ethiopia: a cross-sectional study. Int Breastfeed / 2015; 10:1.

24. Setegn T, Belachew T, Gerbaba M, Deribe K, Deribew A, Biadgilign $\mathrm{S}$. Factors associated with exclusive breastfeeding practices among mothers in Goba district, south east Ethiopia: a crosssectional study. Int Breastfeed I 2012; 7:17.

25. Sinha B, Chowdhury R, Sankar MJ, et al. Interventions to improve breastfeeding outcomes: a systematic review and meta-analysis. Acta Paediatr 2015; 104:114-34.

26. Santo LC do E, De Oliveira LD, Giugliani ERJ. Factors Associated with Low Incidence of Exclusive Breastfeeding for the First 6 Months. Birth 2007; 34:212-9. 
27. Kim MJ, Kim Y-M, Yoo J-H. Factors affecting exclusive breastfeeding during the first 6 months in Korea. Pediatr Int 2013; 55:177-80.

28. Kulkarni R, Anjenaya S, Gujar R. Breast feeding practices in an urban community of Kalamboli, Navi Mumbai. Indian I Community Med 2004; 29:179-85.

29. Abekah-Nkrumah G, Antwi MY, Nkrumah J, Gbagbo FY. Examining working mothers' experience of exclusive breastfeeding in Ghana. Int Breastfeed I 2020; 15:56.

30. Chen J, Xin T, Gaoshan J, et al. The association between work related factors and breastfeeding practices among Chinese working mothers: a mixed-method approach. Int Breastfeed I $2019 ; 14: 28$

31. Rapid Survey on Children 2013. India Fact Sheet. [Internet]. Ministry of Women and Child Development Government of India; 2014 Last Accessed Date: 16.08.2020. Available from: http://wcd.nic.in/sites/default/files/RSOC\%20FACT\%20 SHEETS\%20Final.pdf .

32. Dasoqi KA, Safadi R, Badran E, Basha AS, Jordan S, Ahmad M. Initiation and continuation of breastfeeding among Jordanian first-time mothers: a prospective cohort study. Int I Womens Health 2018;10:571-7.

33. Hendaus MA, Alhammadi AH, Khan S, Osman S, Hamad A Breastfeeding rates and barriers: a report from the state of Qatar. Int J Womens Health 2018;10:467-75.

34. Raheel H, Tharkar S. Why mothers are not exclusively breast feeding their babies till 6 months of age? Knowledge and practices data from two large cities of the Kingdom of Saudi Arabia. Sudan J Paediatr 2018; 18:28-38.

35. Ratnayake HE, Rowel D. Prevalence of exclusive breastfeeding and barriers for its continuation up to six months in Kandy district, Sri Lanka. Int Breastfeed J 2018; 13:36.

36. Nishimura H, Krupp K, Gowda S, Srinivas V, Arun A, Madhivanan P. Determinants of exclusive breastfeeding in rural South India. Int Breastfeed / 2018; 13:40.

37. Pandey S, Tiwari K, Senarath U, Agho KE, Dibley MJ, Network (SAIFRN)* for the SAIFR. Determinants of Infant and Young Child Feeding Practices in Nepal: Secondary Data Analysis of Demographic and Health Survey 2006. Food Nutr Bull 2010; 31:334-51.

38. Regan J, Thompson A, DeFranco E. the influence of mode of delivery on breastfeeding initiation in women with a prior cesarean delivery: a population-based study. Breastfeed Med 2013; 8:181-6.

39. Watt S, Sword W, Sheehan D, et al. The Effect of Delivery Method on Breastfeeding Initiation from the The Ontario Mother and Infant Study (TOMIS) III. J Obstet Gynecol Neonatal Nurs 2012; 41:728-37.

40. Rowe-Murray HJ, Fisher JRW. baby friendly hospital practices: cesarean section is a persistent barrier to early initiation of breastfeeding. Birth 2002; 29:124-31.

41. Meedya S, Fahy K, Kable A. Factors that positively influence breastfeeding duration to 6 months: a literature review. Women Birth 2010; 23:135-45.

42. Organization W, UNICEF. Global strategy for infant and young child feeding. World Health Organization; 2003.

43. Hackett KM, Mukta US, Jalal CSB, Sellen DW. A qualitative study exploring perceived barriers to infant feeding and caregiving among adolescent girls and young women in rural Bangladesh. BMC Public Health 2015; 15:771.

44. Rahi M, Taneja D, Misra A, Mathur N, Badhan S. Newborn care practices in an urban slum of Delhi. Indian I Med Sci 2006; 60:506-13.

45. Emmanuel A. A literature review of the factors that influence breastfeeding: An application of the health belief model. Int I Nurs Health Sci 2015; 2:28-36.

46. Verma A, Dixit P. Knowledge and practices of exclusive breastfeeding among women in rural Uttar Pradesh. J Neonatal Biol 2016; 5:228.

47. Alzaheb RA. A Review of the factors associated with the timely initiation of breastfeeding and exclusive breastfeeding in the Middle East. Clin Med Insights Pediatr 2017;11:1179556517748912. doi: 10.1177/1179556517748912.

48. Chudasama R, Patel P, Kavishwar A. Breastfeeding initiation practice and factors affecting breastfeeding in South Gujarat region of India. Internet J Family Pract 2008; 7:1-7.

49. Patil S, Hasamnis A, Pathare R, Parmar A. Prevalence of exclusive breast feeding and its correlates in an urban slum in western India. leJSME 2009; 3:14-8. 